\title{
Direct posterior coronal restoration: Practice of students clinicians of the odonto- stomatological consultation and treatment center of Abidjan
}

\author{
Marie Adou-Assoumou ${ }^{1}$, Aline A. Krah-Sinan ${ }^{2, *}$, Stéphane X. Djolée ${ }^{3}, J$ anas A. Adou ${ }^{4}$, Edmée C. Mansilla $^{5}$ \\ ${ }^{\mathbf{1 , 2 , 4}}$ Associate Professor, ${ }^{3}$ Clinic Head Assistant, ${ }^{5}$ Professor, Dept. of Conservative Odontology \& Endodontics, Faculty of \\ Odonto-Stomatology, Félix Houphouët Boigny University, Abidjan, Côte d'Ivoire
}

\section{*Corresponding Author:}

Email: aline_sinan@yahoo.fr

\begin{abstract}
Introduction: Dental amalgam and adhesive materials (composite resin and glass ionomer cement) are commonly used for occluso-functional and esthetic teeth rehabilitation. The objective of this study was to assess direct posterior coronal restorative materials used by 19 students' clinicians' classes.

Material and Methods: A retrospective study was carried out to collect from students' performed care records the different types of restorations' data from 1994 to 2016 . The choice of materials is estimated according to education levels [ $1^{\text {st }}$ year Master (M1), $2^{\text {nd }}$ year Master (M2) $1^{\text {st }}$ year Doctorate (D1)]. The collected data was processed with SPSS software. Pearson chi-square test was used to compare qualitative variables and the significance threshold set at $5 \%$.

Results: From 1994 to 2016, there were 11 registers recording 19 students' classes distributed according to education levels. In all, 6,033 posterior teeth procedures were performed on 3,134 patients. These restorations refer to $73.4 \%$ of molars and $26.6 \%$ of premolars. In 1994, the amalgam was used for $99.86 \%$ and adhesive materials for $0.14 \%$. However, in 2016 , these same materials were frequently used in $78.86 \%$ to $21.14 \%$ for the amalgam. Between the first year of Master (M1) and the last year (D1), the use of amalgam declines over the years while that of adhesive materials increases.

Conclusion: It seems, in recent years, that under the influence of educational approaches centered on adhesive materials, youngest practitioners are using composite resin more for posterior restorations compared with senior practitioners.
\end{abstract}

Keywords: Adhesive materials, Dental amalgam, Posterior coronal restorations, Students clinicians.

\section{Introduction}

Coronal restoration of a tooth is a procedure to make up for a loss of dental substance for biological, functional and aesthetic purposes. ${ }^{1}$ Direct coronal restorations are very common in daily practice. ${ }^{2}$ They require two types of materials: non-adhesive materials with dental amalgam and so-called adhesive materials with composite resin and Glass Ionomer Cement (GIC). For a long time, dental amalgam, due to its mechanical properties, had been the only restorative material recommended for posterior teeth restoration. ${ }^{3}$ However, mechanical properties of socalled adhesive materials, recommended, in the past, exclusively for anterior teeth restorations due to their aesthetic quality, have been improved to be used for posterior teeth also. ${ }^{4}$ Hence, a corollary of restoration is the development of a new therapeutic concept called "preventive medical" which is based on the protection of dental structures. ${ }^{5,6}$ Thus, cavity layouts for amalgam with a significant disposal of dental tissues are diminishing in favor of adhesive restorations. Moreover, because of its mercury content, its use has caused controversies regarding the intoxication of patients and caregivers. ${ }^{78}$ At the dental school of Abidjan, the Odonto-Stomatological Consultation and Treatment Center (OSCTC) has a sole purpose of clinical training of students. These potential dental surgeons perform coronal restorations under the supervision of the department of Conservative Odontology and Endodontics (COE) teachers. Once the supervisor approves the therapeutic indications, various operating sequences are followed and validated during the treatment. However, students have certain autonomy in choosing the restorative material according to the decision agreed on with the patient. The purpose of this study was to assess direct posterior coronal restorative materials used by 19 students' clinicians' classes.

\section{Material and Methods}

This is a descriptive retrospective study based on COE service records. This service records students' performed procedures. For each academic year, a register per care center is made available to all students clinicians. This registration system was set up from the first fully trained class of Dental Surgeons in Abidjan that is for the 1990-1991 academic year. Until 2011, all COE clinical sessions were held at only one of the two OSCTC sites. From 2014, COE clinical sessions are expanded to both sites with one registry per site and one extra clinical year, the $6^{\text {th }}$ year. All records prior to 2017 have been used in this study. In these, all posterior teeth (premolars and molars) coronal restorations with a definite coronal filling material were selected. Only procedures with complete information (file number, patient's identification, date of treatment, number of restored teeth, material type) along a supervisor's signature certifying the effective completion of the treatment were included. The data collected was processed with SPSS software. Qualitative variables 
were compared using the Pearson chi-square test, a significance threshold set at $5 \%$.

\section{Results}

Available registers are from 1994, 2003 to 2006 and 2014 to 2016. Each year is composed of two classes $\left(4^{\text {th }}\right.$ and $5^{\text {th }}$ years) for the first five years and three classes $\left(4^{\text {th }}, 5^{\text {th }}\right.$ and $6^{\text {th }}$ years $)$ for the last three years. Out of a total of 28 registers, only 11 had 19 classes divided by education level $\left(4^{\text {th }}, 5^{\text {th }}\right.$ and $6^{\text {th }}$ years). On all classes, 6,033 treatments which met the inclusion criteria were selected and these coronal restorations on posterior teeth were done on 3,134 patients.

Performed treatments results, their distribution according to years and materials used are presented in the format of tables and figures.

\section{Discussion}

\section{Study protocol}

Available registers have significant years' gaps. This is due to the 2011 crisis in the country which resulted in looting and destruction of goods and properties nationwide. The UFR did not escape the crisis and suffered significant losses of its equipment and other materials. Only available registers made this study possible.

\section{Number of direct posterior coronal restorations by years}

Results show that 1994, 2014 and 2016 are marked by an increase in student performed treatments, estimated at an average of $10 \%$ (Table 1 and 2). The variable number of students, according to classes could explain these gaps. Indeed, establishing the common core since 1992 which gather together first year health sciences students (medicine, pharmacy and odontology), has contributed to the reduction of the number of students since 1995. The class of 1994 which did not undergo this scheme has a large number of students, reflecting the high number of care provided. Moreover, beside the socio-political crisis, the OSCTC was closed from 2011 until the end of 2013. During that time, students received theoretical training only, consequently, the health center reopened in 2014, accumulating several classes of students clinicians: one $4^{\text {th }}$ year class, two classes of $5^{\text {th }}$ year and one $6^{\text {th }}$ year. This justifies the high number of performed procedures during that year. From 2016, the decline in the number of procedures was directly due to a tendency to normalization with one class by education level $4^{\text {th, }} 5^{\text {th }}$ years and very few students in a $6^{\text {th }}$ year.

\section{Types of posterior coronal restorations by education level}

This study shows that students from $5^{\text {th }}$ year class have performed more procedures than their counterparts (Fig. 1). This is due to the fact that they have at least two years of clinical experience and more procedures are required from them than from $4^{\text {th }}$ year students. Regarding their counterparts from $6^{\text {th }}$ year class, they are subjected to performing specific procedures for their end of clinical internship memoir. Of all classes, amalgam remains the most used material (Fig. 2). Its superior mechanical properties, ease of handling and low cost could justify its use in coronal restorations of most of our population in a low socio-economic situation. ${ }^{3.9}$ However, compared with previous academic years, the use of amalgam has been decreasing over the years, while adhesive materials use increases (Fig. 3). The teaching which insists more on adhesive materials according to the new therapeutic concept has impacted this development. ${ }^{10}$ Indeed, amalgams are being replaced by aesthetic materials in posterior coronal restorations due to the controversy over their use. ${ }^{4,11}$

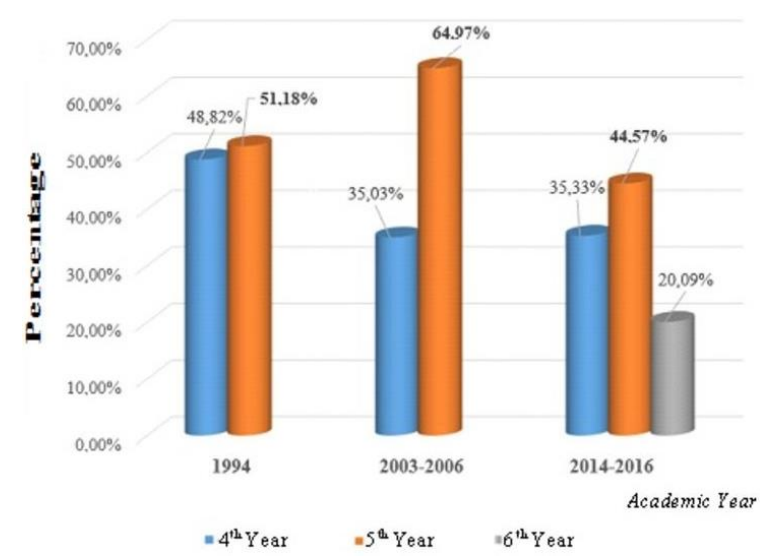

Fig. 1: Activities volume per academic year: $5^{\text {th }}$ year students perform more direct coronal restorations than their counterparts $(P=0.000)$

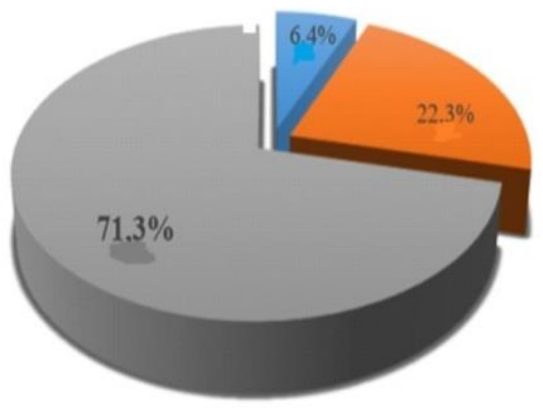

$\approx C V I=$ Composite $=$ Amalgam

Fig. 2: Distribution of used direct restorative materials: Dental amalgam is by far $(\mathbf{7 1 . 3 \%})$ the most used material on all performed procedures from 1994 to 2016 


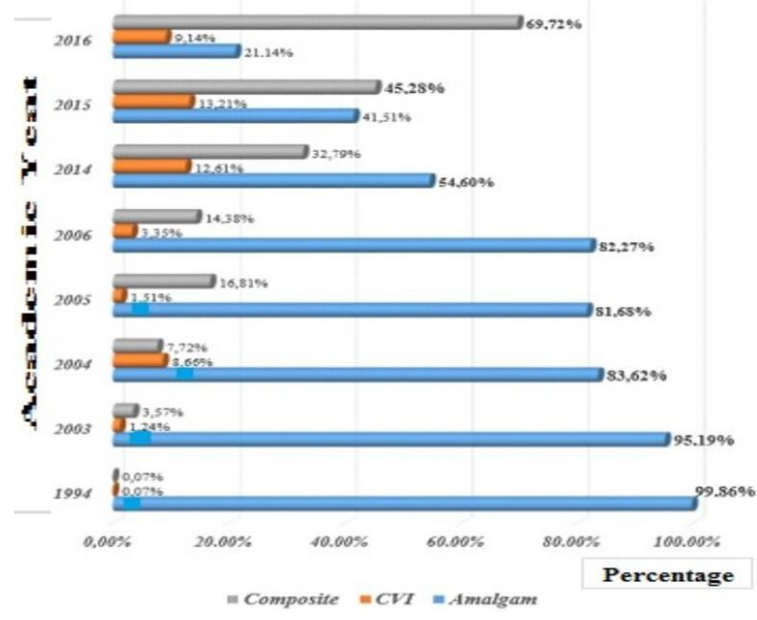

Fig. 3: Frequency use of restorative materials per year: Dental amalgam was practically the only material used in 1994, but twenty years later (2015), the composite is the most used material with a constant evolution the following year

Compared with education level, results also show a decrease in amalgams use for adhesives from the $4^{\text {th }}$ to the $5^{\text {th }}$ year class (Fig. 4). At the beginning of clinical training, to quickly validate their required amount of clinical procedures, less experienced students tend to use the amalgam due to its ease to implement. $6^{\text {th }}$ year students, though, who have at least three years of clinical experience, are more skillful and therefore handle adhesive materials with much more ease (Fig. 4). There is, indeed, a real tendency to the use of composite resin for posterior teeth restorations. The choice of this type of material at the end of clinical training of Ivorian students matches that of students in Ireland, the United Kingdom, the United States and Israel. $^{12,14}$ Other findings reveal that professional experience is a factor influencing the choice of material. ${ }^{15}$ It seems that in recent years, under the influence of educational approaches centered on adhesive materials, youngest practitioners are more keen to posterior restorations with composite resin compared with seniors. ${ }^{16}$

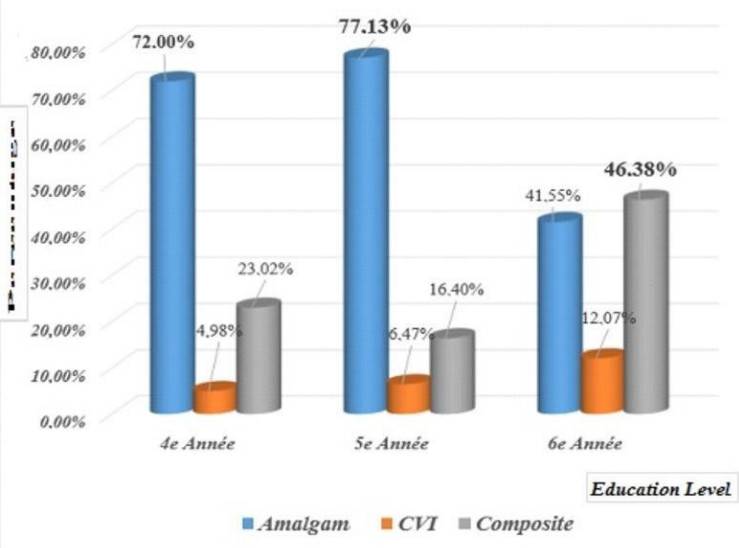

Fig. 4: Frequency of use of restorative materials according to academic year: On all restored teeth, $4^{\text {th }}$ and $5^{\text {th }}$ year students used amalgam mainly; for $6^{\text {th }}$ year students, there was a virtual balance between amalgam and composite with a slight increase in favor of adhesive material $(P=0.000)$

Table 1: Number of coronal restorations by students per years, direct posterior coronal restorations were the most performed during 1994, 2014 and 2016

\begin{tabular}{|l|c|c|}
\hline $\begin{array}{c}\text { Academic } \\
\text { year }\end{array}$ & $\begin{array}{c}\text { Effective } \\
\text { (n) }\end{array}$ & $\begin{array}{c}\text { Percentage } \\
(\mathbf{\%})\end{array}$ \\
\hline 1994 & 1,391 & 23.1 \\
\hline 2003 & 645 & 10.7 \\
\hline 2004 & 635 & 10.5 \\
\hline 2005 & 464 & 7.7 \\
\hline 2006 & 300 & 5.0 \\
\hline 2014 & 1,578 & 26.2 \\
\hline 2015 & 320 & 5.3 \\
\hline 2016 & 700 & 11.6 \\
\hline Total & 6,033 & 100.0 \\
\hline
\end{tabular}

The frequency of direct coronal restorations in 1994, 2014 and 2016 shows an increase in performed procedures by students.

Table 2: Performed treatments before 2000 (1994), during the first decade of 2000 (2003-2006) and during the last decade of 2000 (2014-2016)

\begin{tabular}{|l|c|c|c|c|}
\hline \multirow{2}{*}{$\begin{array}{c}\text { Classification } \\
\text { according to 2000 }\end{array}$} & \multicolumn{2}{|c|}{ Patients } & \multicolumn{2}{c|}{ Coronal restorations } \\
\cline { 2 - 5 } & $\begin{array}{c}\text { Effective } \\
(\mathbf{n})\end{array}$ & $\begin{array}{c}\text { Percentage } \\
(\mathbf{\%})\end{array}$ & $\begin{array}{c}\text { Effective } \\
(\mathbf{n})\end{array}$ & $\begin{array}{c}\text { Percentage } \\
(\mathbf{\%})\end{array}$ \\
\hline Before (1994) & 724 & 23 & 1,391 & 23 \\
\hline $1^{\text {st }}$ decade (2003-2006) & 1,021 & 33 & 2,044 & 34 \\
\hline $2^{\text {nd }}$ decade (2014-2016) & 1,349 & 44 & 2,598 & 43 \\
\hline Total & 3,134 & & 6,033 & \\
\hline
\end{tabular}

The distribution of these treatments according to three periods, before 2000, during the first decade of 2000 and the last decade of 2000 , shows an increase of carried out procedures respectively passing from $23 \%$, $34 \%$ to $43 \%$ of restorative treatments. 


\section{Conclusion}

This study highlights the various posterior coronal restorative materials used by students' clinicians over the years. Dental amalgam remains the most used material, but a trend towards adhesive materials seems to be rising in recent years. This is a reflection of the teaching that emphasizes the use of adhesive materials in accordance with new therapeutic recommendations.

Funding: No funding sources.

Conflict of interest: None declared.

\section{References}

1. Manhart J, Chen H, Hamm G, Hickel R. Buonocore Memorial Lecture. Review of the clinical survival of direct and indirect restorations in posterior teeth of the permanent dentition. Oper Dent 2004;29(5):481-508.

2. Afrashtehfar KI, Ahmadi M, Emami E, Abi-Nader S, Tamimi F. Failure of single-unit restorations on root filled posterior teeth: a systematic review. Int Endod J 2017;50(10):951-66.

3. Colon P, Pradelle-Plasse N, Galland J. Evaluation of the long-term corrosion behavior of dental amalgams: influence of palladium addition and particle morphology. Dent Mater 2003;19(3):232-9.

4. Rasines-Alcaraz MG, Veitz-Keenan A, Sahrmann P, Schmidlin PR, Davis D, Iheozor-Ejiofor Z. Direct composite resin fillings versus amalgam fillings for permanent or adult posterior teeth. Cochrane Database Syst Rev 2014;31(3):CD005620.

5. Mount GJ, Tyas JM, Duke ES, Hume WR, Lasfargues JJ, Kaleka R.A proposal for a new classification of lesions of exposed tooth surfaces. Int Dent J 2006;56(2):82-91.

6. Lasfargues JJ, Bonte E, Guerrieri A, FezzaniL. Minimal intervention dentistry: part 6 . Caries inhibition by resin infiltration. Br Dent J 2013;214(2):53-9.

7. Bengtsson UG, Hylander LD. Increased mercury emissions from modern dental amalgams. Biometals 2017;30(2):277-83.

8. Nagpal N, Bettiol SS, Isham A, Hoang H, Crocombe LA. A Review of Mercury Exposure and Health of Dental Personnel. Saf Health Work 2017;8(1):1-10.
9. Correa MB, Peres MA, Peres KG, Horta BL, Barros AJ, Demarco FF.Do socioeconomic determinants affect the quality of posterior dental restorations? A multilevel approach. J Dent 2013;41(11):960-7.

10. Wilson $\mathrm{NH}$, Lynch $\mathrm{CD}$. The teaching of posterior resin composites: planning for the future based on 25 years of research. J Dent 2014;42(5):503-16.

11. Alvanforoush N, Palamara J, Wong RH, Burrow MF. Comparison between published clinical success of direct resin composite restorations in vital posterior teeth in 1995-2005 and 2006-2016 periods. Aust Dent J 2017;62(2):132-45.

12. Lynch CD, McConnell RJ, Wilson NH. Teaching of posterior composite resin restoration in undergraduate dental schools in Ireland and the United Kingdom. Eur J Dent Educ 2006;10:38-43.

13. Lynch CD, Robert J, McConnell RJ, Wilson NH. Teaching the placement of posterior resin-based composite restorations in U.S. dental schools. J Am Dent Assoc 2006;137:619-25.

14. Ben-Gal G, Weiss E. Trends in material choice for posterior restorations in an Israeli dental school: composite resin versus amalgam. J Dent Educ 2011;75(12):1590-5.

15. Khalaf ME, Alomari QD, Omar R. Factors relating to usage patterns of amalgam and resin composite for posterior restorations-a prospective analysis. J Dent 2014;42(7):785-92.

16. Rey R, Nimmo S, Childs GS, Behar-Horenstein LS. Curriculum time compared to clinical procedures in amalgam and composite posterior restorations in U.S. dental schools: a preliminary study. J Dent Educ 2015;79(3):331-6.

How to cite the article: Krah-Sinan A., AdouAssoumou M., Djolé S, Adou J., Mansilla E. Direct posterior coronal restoration: Practice of students clinicians of the odonto-stomatological consultation and treatment center of Abidjan. IP Indian J Conserv Endod 2018;3(3):82-85. 